\title{
Straw bale fire test on cement plaster mixes
}

\author{
G. Garas, M. Allam \& K. Mamdouh \\ Civil Eng. Dept., National Research Center, Cairo, Egypt
}

\begin{abstract}
The use of plastered straw bales for wall construction in residential and light commercial buildings has increased significantly all over the world. The performance of straw bale walls under fire exposure is an item of major importance in securing construction.

This paper presents a fire resistance test on different cement plaster mixes applied on straw bales of thickness $45 \mathrm{~cm}$. The test was conducted on the samples' surface for almost 2 hours using direct flame. A thermal sensor was installed on the sample side opposite to the flame side to record the transmission of heat through the plastered bales. The results showed that bales survived fire penetration in excess of 2 hours after which the flame was discontinued.

It was concluded that mixes containing higher percentages of cement content exhibit more fire resistance than those with less cement content. It was also noticed that the increase in heat transmission through the bales (between both sides) did not exceed $5^{\circ} \mathrm{C}$ in all samples.

Keywords: straw bales, fire resistance, fire test, cement plaster, cement content, lime content, direct flame, heat transmission, exposure period.
\end{abstract}

\section{Introduction}

The fire resistive properties of materials are measured and specified according to common standards expressed in terms that are applicable alike to a variety of materials, situations and conditions of exposure. The performance of these materials is defined as the period of resistance to standard exposure elapsing before the first critical point in behavior is observed.

There are various methods known as "standard fire tests" to measure the different materials' fire resistance, and the performance or exposure period is expressed as 6 hours, 2 hours, $1 / 2$ hour etc. The ASTM E-119 is identical or 
similar to those standard test methods. Examples of these standard tests are: UL 263, UBC7-1 [1].

Building codes express the fire safety of walls as a function of fire resistance, meaning how long a conflagration can exist on one side of the wall in question before enough heat is transmitted through the wall to ignite materials on the other side, even if fire has not actually breached the wall [2].

\subsection{Plastered straw bale behavior}

Fire requires high temperature, fuel, and oxygen; compressing the straw into a dense block dramatically decreases the ability of oxygen to feed a fire at the straw. After the surface of a bale or bale wall has been charred (providing that the wall of exposed bales remains intact), the worst it will generally do is smolder. This resistance to rapid combustion has been observed during a few accidental fires during construction of bale buildings [2].

Bob Theis, 2003 reported that during a lab test, called "corner test", on unplastered bales at the Richmond Field Station of the University of California in March 1996, a burning waste basket was placed adjacent to the wall corner. When exposed to the fire source, the surfaces of the bales rapidly charred, after which there was no observable effect. At the test's completion, the team was asked to remove the charred bales from the test chamber to a dumpster-without first subjecting the chamber to a soaking down. At this stage the bales fell apart, and sparks inside the straw had sufficient oxygen to develop into open flame.

In general, most of the reported ASTM E-119 lab fire tests verified that once a bale wall has been plastered on both faces, the combination of an incombustible surface and an insulating interior that neither burns well nor melts makes a straw bale wall a very fire-resistive assembly.

However, it should be denoted that 14 reports of fires in straw bale buildings during and after construction were collected. These range in severity from the inconsequential flash of flames across the loose surface straw of an unplastered wall, to the complete loss of the structure. The best single correlation with extent of damage seems to be whether the plaster was in place at the time of the fire or not.

\subsection{Spontaneous combustion and real fire hazard}

All previous facts are true for plastered rice straw bales. However, unbaled and loose straw is considered extremely combustible. The large amounts of loose straw that accumulates during construction are considered to be a serious fire hazard. Smoking, welding or any other spark or flame-producing activities should not be undertaken in the vicinity of loose straw. It is therefore recommended to keep loose straw raked away from the walls to minimize the risk of any accidental fire spreading into the unplastered walls [3].

\section{Scope of the research}

The test undertaken in this paper provides a relative measure of the fire-testresponse for 3 comparable cement-plaster mixes under the same fire exposure 
condition. The cement mixes were applied with a constant layer of $5 \mathrm{~cm}$ thickness on all sides of the bales. All the bales were local rice straw bales from the same supplier having the same dimensions, moisture content, weight and undertaken the same environmental conditions.

Fire exposure is maintained using a direct flame of the same source under atmospheric temperature. This exposure condition is not representative of all fire conditions applied in the standard fire tests because conditions vary with changes in the amount, nature and distribution of fire loading, ventilation, compartment size and configuration. Variation from the test conditions or specimen construction, such as size, materials, method of assembly, also affects the firetest-response.

The test was applied on single plastered bales under no compression and all specimens were tested for a complete 2-hours direct flame exposure after which the test was ended. The test standard does not provide information as to performance of specimens constructed with components or lengths other than those tested.

\section{Test procedure and conditions}

The test procedure was as follows:

- First the area of the plastered samples that was subjected to the flame was identified by a square with dimension $20 \mathrm{~cm} \times 20 \mathrm{~cm}$ at the center of which the nozzle of the fire source was directed, (Figure 1).

- The samples were of thickness $45 \mathrm{~cm}$ and were coated with 2 coats of plaster $2.5 \mathrm{~cm}$ each from all faces.

- The nozzle of the flame was installed away from the samples' surface with about 20 to $25 \mathrm{~cm}$.

- The test continued for 2 hours after which the flame was removed.

- A sensor of sensitivity ranging from $-40{ }^{\circ} \mathrm{C}$ to $80{ }^{\circ} \mathrm{C}$ was installed on the opposite surface of the flame facing the center of the marked square, (Figure 2).

- The sensor was connected to a PC to monitor the heat transmission through the bales during the test.

- The data from the sensors was recorded every $15 \mathrm{sec}$.

- The test was conducted in the open air under atmospheric temperature to predict the performance of the cement mixes under actual conditions.

- The specimens were not subjected to any load but only their own weight. 


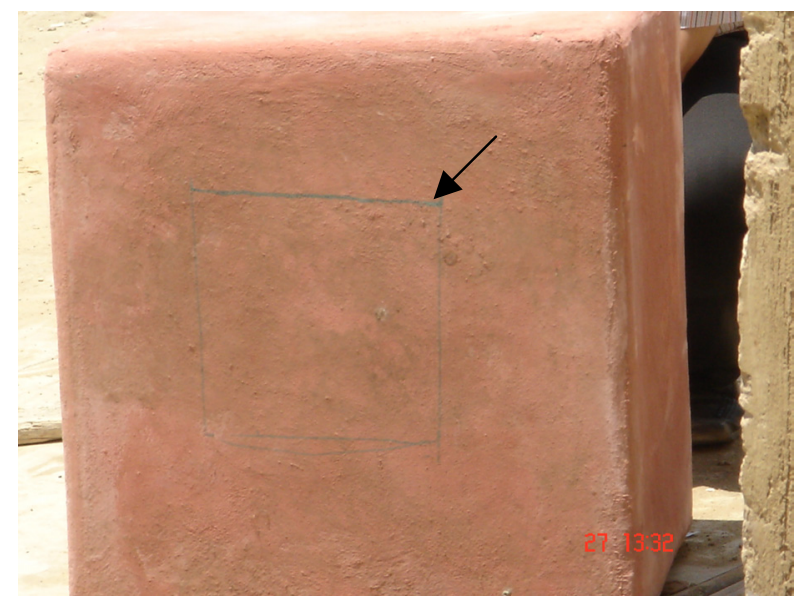

Figure 1: $\quad$ Area subjected to flame.

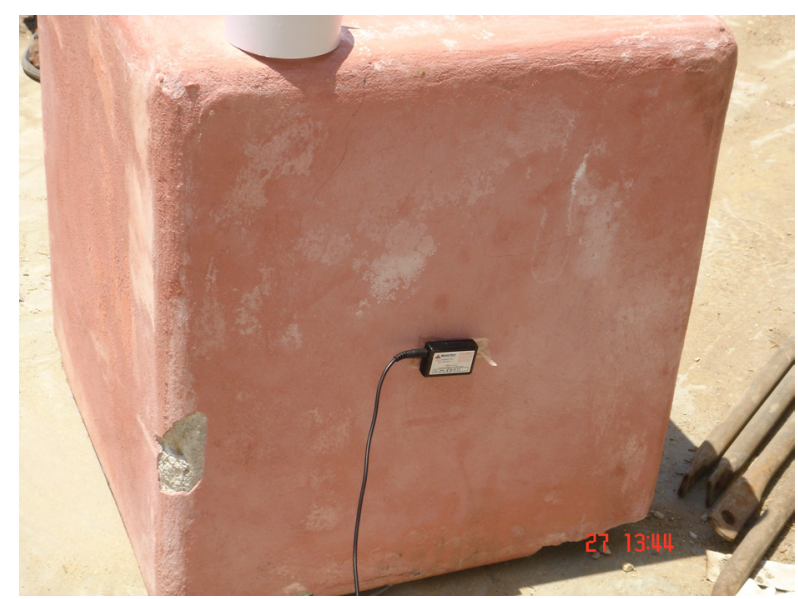

Figure 2: $\quad$ Opposite side attached to the sensor.

\section{Test specimen construction}

Three mixes of cement stucco were used for this test as follows:

Mix A cement: lime : sand (1: $0: 3)$

Mix B cement: lime : sand $(1: 1: 6)$

Mix C cement: lime : sand (1:2:9)

The rectangular samples of straw bales $(0.5 * 0.5 * 0.45 \mathrm{~m})$, (length $*$ height * width) were prepared and tied with two polypropylene ties per bale. The samples were covered from all faces with galvanized reinforcing steel mesh with 
adequate overlap. The steel mesh was fastened to the bales' skin using curved steel pins.

The three different stucco mixes described previously were applied to straw bale specimens using hand trowels in order to get a uniform thickness of $2.5 \mathrm{~cm}$ for each coat above the bale's skin. Samples were then cured by wetting twice daily for a period of 7 days after which they were covered with plastic sheets to maintain its humidity. The samples were left to dry and sit for 36 days prior to testing.

\section{Results and observations}

The surface of all specimens that were directly exposed to the hose of the flame maintained the conflagration for the 2 hours without heat transmission through the wall to ignite the material on the other side.

Specimen one with the highest lime content, Mix C cement: lime: sand (1: $2: 9)$, developed a visible crack at the specimen highest corner above the exposed area after 25 minutes (Figure 3 ). The crack increased in size by the time and smoke was visible coming out of the crack (Figure 4). Hair cracks appeared on the exposed side of the specimen after about 90 minutes of the continuous flame exposure (Figure 5). The smoke coming out of the upper crack was extinguished with water at the end of the test. After 9 hours of the test completion the specimen was still smoking which required complete soaking down of the specimen (Figure 6).

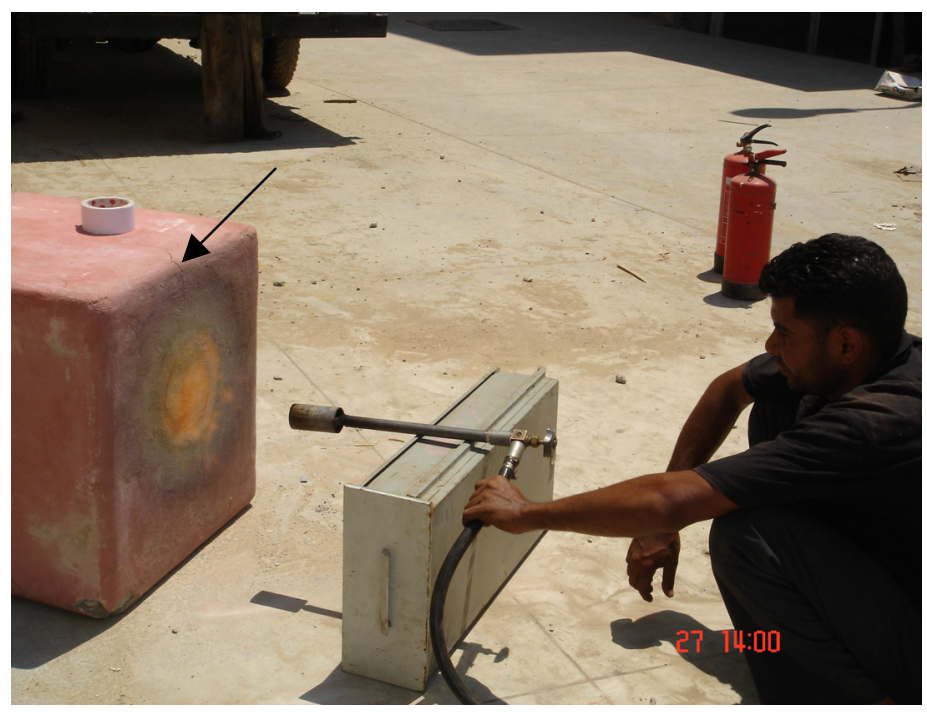

Figure 3: $\quad$ The appearance of a crack on Specimen Mix C after 25 minutes.

The atmospheric temperature at the beginning of the test for specimen one was $33^{\circ} \mathrm{C}$ and ended at $38^{\circ} \mathrm{C}$ as recorded by the sensor on the opposite side of 


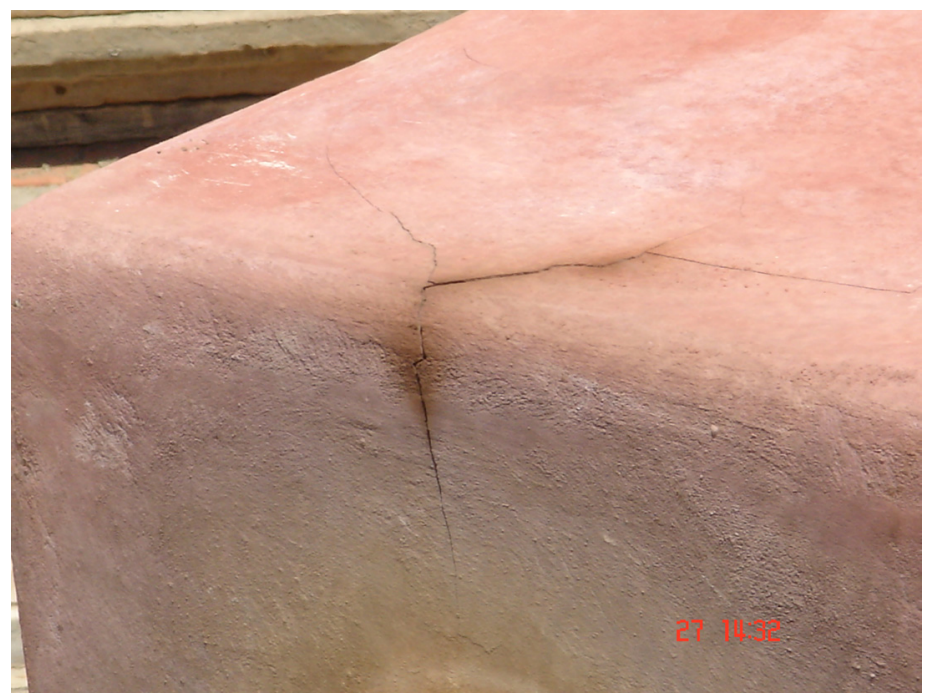

Figure 4: The increase in the crack width in specimen of Mix C after 1 hour.

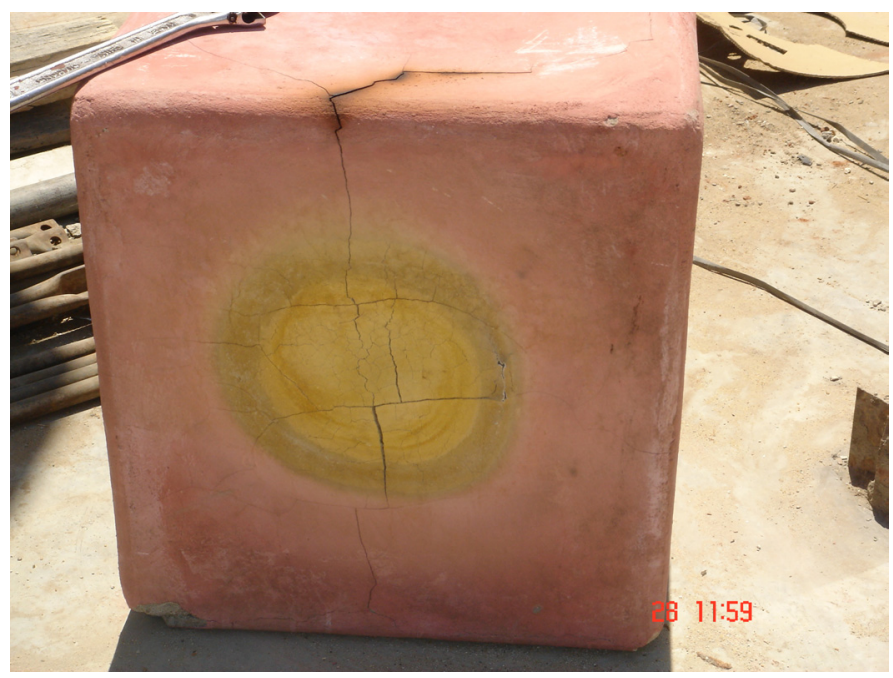

Figure 5: $\quad$ The specimen Mix C after 9 hours of test completion.

the flame on specimen Mix C. The temperature increased gradually during the total life time of the test to record a total increase of $5.3^{\circ} \mathrm{C}$ (Figure 7). The initial humidity reading of the sensor was $37 \%$ at the beginning of the test.

Specimen two (Mix B cement: lime: sand (1:1:6) with a lime content half that of Mix C, continued for the two hours of the test and no cracks were noticed till the end (Figure 8). The maximum temperature increase transferred through the specimen width was about $5.3^{\circ} \mathrm{C}$ during the two hours (Figure 9). 


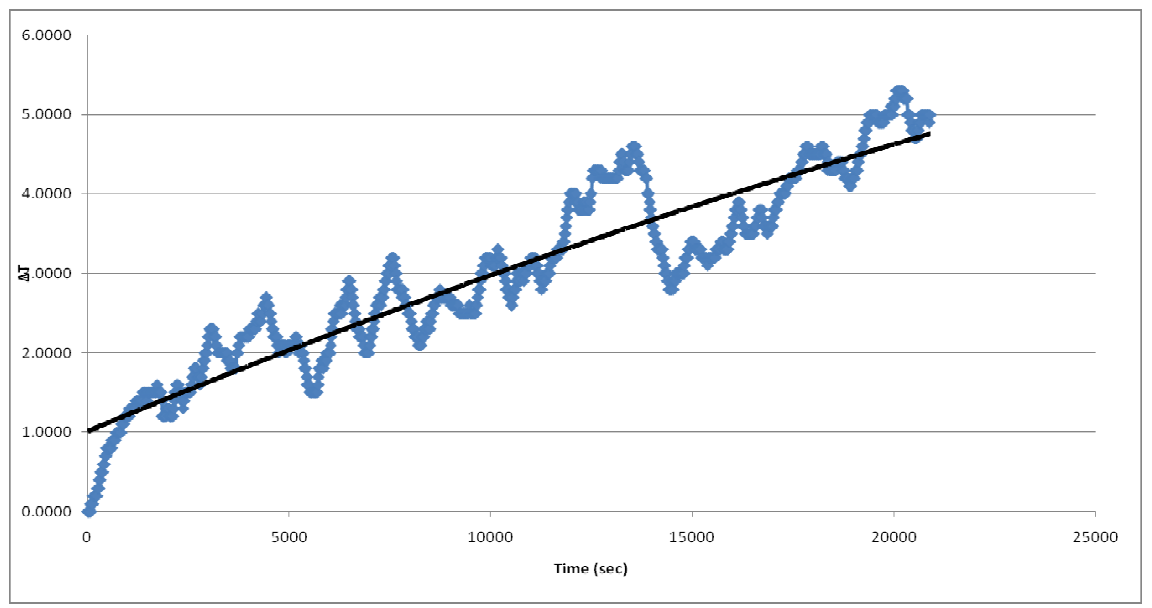

Figure 6: The increase in heat Transfer through Specimen Mix C.

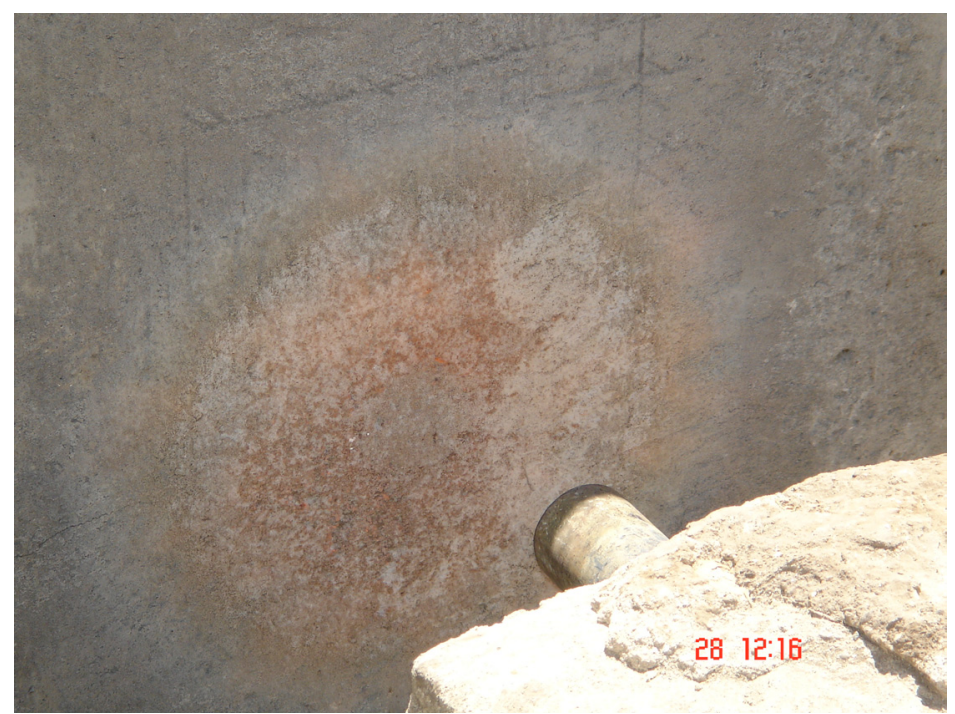

Figure 7: $\quad$ Specimen Mix B after 16 minutes of test beginning.

Specimen three (Mix A cement: lime: sand (1:0:3) without any lime content showed no signs of minute change during the overall life of the test Figure (10). The sensor showed the same amount of temperature increase through out the total exposure of specimen Mix A. However, some fluctuation in the sensor readings were recorded after one and a half hour of the test life time due to the increase in wind speed and lasted for about ten minutes. 


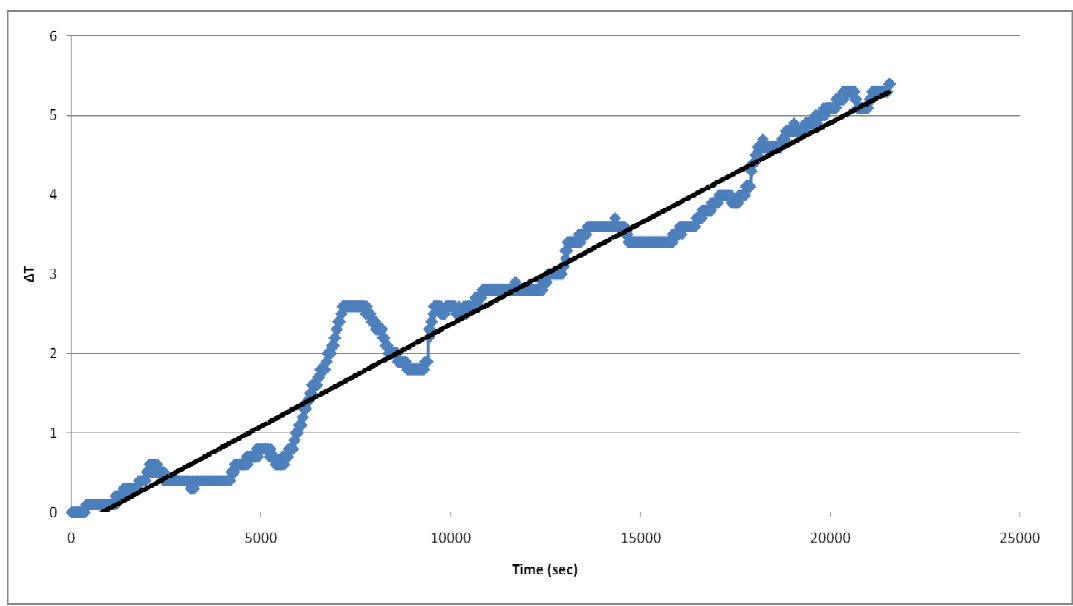

Figure 8: $\quad$ The increase in the heat transfer through specimen Mix B.

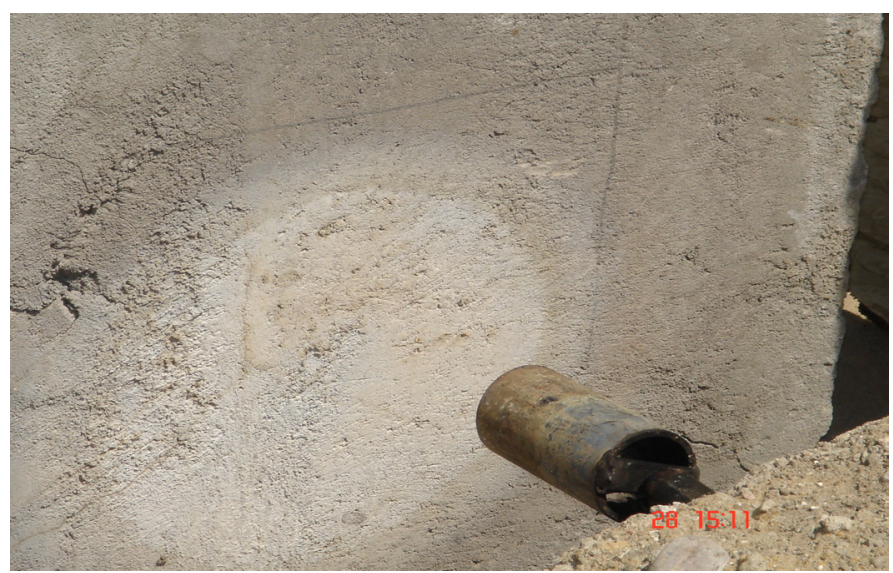

Figure 9: $\quad$ Specimen Mix A after 15 minutes of test beginning.

\section{Discussion and conclusions}

This test is conducted to monitor and describe the behavior of various cement plaster mixes applied as a layer of $5 \mathrm{~cm}$ thickness on rice straw bales after exposure to heat and flame under controlled conditions. The results of this test are one factor of several others used in assessing predicted performance of actual cement plastered straw bale walls. The test is regarded successful as all specimens sustained the two-hour direct fire exposure without passage of the flame or even gases hot enough to ignite the internal straw to reach the opposite side of the plastered bale. However, cracks appeared at the weak corner of 
specimen $\mathrm{C}$ with the highest lime content while by decreasing this component and increasing the amount of cement in the mix no cracks were reported. Transmission of heat throughout the walls of the specimens with three different mixes did not exceed $5.5^{\circ} \mathrm{C}$ above its initial temperature when measured from the unexposed surface opposite to the flame. This indicates that the components of the plaster mixes do not affect the transmission of heat through the bale. The width and density of the bales which remained constant for all the specimens is considered to be the main guiding factor for heat transmittal.

These results meet the conditions of acceptance of the ASTM E119 for testing bearing walls and partitions taking into consideration that the test was applied on single cement plastered bales. Previous tests conducted by Garas et al. 2008, on the same group of mixes to examine its compressive strength, modulus of rupture and modulus of elasticity were in favor of mixes $\mathrm{A}$ and $\mathrm{B}$ indicating higher efficiency by increasing the cement content and decreasing the amount of lime in the mix [4]. It is therefore recommended for further research to apply the same test procedure on a full scale load bearing wall plastered with mixes A (no lime content) and B (one part of lime and one part of cement) to simulate field use conditions.

\section{References}

[1] Test Report prepared for Ecological Building Network, ASTM E 119-05a, Fire Tests of Building Construction and Materials, 2 HR fire Resistance Test of a Non Load Bearing wheat straw bale wall, July 2007,

[2] Theis, B., Straw bale Fire Safety A review of testing and experience to date, July 30, 2003.

[3] Magwood, C. et al, More Straw Bale Buildings: A complete Guide to Designing and Building with Straw. New Society Publishers, Canada, April 2005.

[4] Garas, G., Allam, M. \& Ragab, A., Towards Sustainable Waste Management Through Structural Testing of Rice Straw bale Cement Plasters, Waste Management and the Environment IV, Ecology and the Environment volume 109, ISB 